\title{
Children's Encounters with Natural Selection During an Interactive Read Aloud
}

\author{
Johanna Frejd ${ }^{1}$ (iD \\ Published online: 4 November 2019 \\ (C) The Author(s) 2019
}

\begin{abstract}
Previous studies have shown that children as young as 5 years of age are able to form a basic understanding of evolution after listening to a storybook about natural selection. This study offers a semiotic exploration of children's meaning making during an interactive read aloud of the same storybook by investigating what children focus on and negotiate during the read aloud. Video data from eight interactive read aloud sessions $(N=24$ children) were analysed using a multimodal approach and contrasted with seven biological concepts intentionally described in the storybook. During the interactive reading, the children focused on all biological concepts at some point. However, apart from the biological concepts, the children also paid attention to other topics during the read aloud. These topics comprised Death, Change in behaviour, Realism, Babies, Milli bugs, and Aesthetics. Throughout the read aloud, a child-centric view of life influenced how the children made meaning about evolution. The findings highlight that through interactive reading, instructional storybooks also become a tool for discussing other aspects that children find important. Overall, the findings contribute with knowledge about the role of interactive read aloud as a pedagogical tool for introducing evolution in early childhood education.
\end{abstract}

Keywords Early childhood · Evolution · Interactive read aloud · Meaning-making processes · Multimodality

\section{Introduction}

Read aloud of storybooks can be more or less scripted. In the Swedish preschool system, read aloud is far from a one-way communication scenario (Cekaite and Björk-Willén 2018). Instead, read aloud can be described as dialogic or interactive. Dialogic reading

Johanna Frejd

johanna.frejd@liu.se

1 Department of Social and Welfare Studies, Linköping University, 60174 Norrköping, Sweden 
(Zevenbergen and Whitehurst 2003) is a strategy where the adult continuously asks questions and prompts and discusses the story to enhance meaning. Interactive reading (Oyler 1996) is characterised by a high level of participation and children are viewed as participants and coconstructers of the read aloud where the reader "genuinely shares, not abandons, authority with the children" (Smolkin and Donovan 2003, p. 28). This suggests that children's spontaneous questions or queries are embraced in the reading activity.

In read aloud, toddlers are more engaged when the reader interacts with the child (GardnerNeblett et al. 2017). Furthermore, by using dialogic strategies prior to, during and after reading, teachers can actively engage children in sharing ideas (Lennox 2013). Dialogic and interactive approaches to read aloud can thus be seen as pedagogical tools for the teacher to engage children in making meaning of a text (cf Wiseman 2011) while the reader has the possibility to engage with what the children say. Consequently, an interactive approach in read aloud enables the reader to gain insight into the connections children make between interpreting the text in light of their own experiences (Oyler 1996).

Several studies have focused on the effects of read aloud in science education. For example, read aloud has been highlighted as a way to teach specific science topics, such as light and colour (Leung 2008) and magnetism (Kalogiannakis et al. 2018). Varelas et al. (2014) have suggested the benefit of combining read aloud of informational texts with hands-on explorations. Varelas et al.'s (2014) study displayed that children extended upon the written text through reasoning. For example, one child connected their everyday experience that earthworms dry out and die when exposed to the sun to a passage in a book describing that earth worms sleep through hot days buried deep in the underground. Varelas et al. (2004) suggest that such "third spaces", i.e. where everyday experiences and scientific explanations provided in texts are linked together, are able to support meaning making.

The science content focus of this paper is natural selection. Several studies have investigated to what extent children can learn about evolution by listening to or reading storybooks (e.g. Browning and Hohenstein 2015; Legare et al. 2013; Shtulman et al. 2016). In two studies by Kelemen et al. (2014) and Emmons et al. (2016) children were taught about evolution through listening to a factual narrative picture storybook called How the piloses evolved skinny noses $^{1}$ (Kelemen and The Child Cognition Lab 2017). The book was developed by the research team with the aim to help children acquire "a complete and cohesive understanding of adaptation without holding any misconceptions" (Emmons et al. 2016, p. 1207). The storybook focuses on the gradual increase of a foraging trait, a skinny trunk, among a population of a fictitious animal species called the piloses. In the storybook, the increase of skinny trunks is described as a consequence of several processes related to evolution, such as inheritance and natural selection. After listening to the storybook, the children's understanding was tested individually in clinical interviews. The results from Kelemen et al. (2014) and Emmons et al. (2016) show that children as young as 5 years old gained a simplified understanding of evolution.

Emmons et al. (2017) have also examined the storybook's impact on 6-year-old and 8-yearold children's ability to perform a "far-reaching transfer" of their knowledge of evolution. The study built on the same methodological design as Kelemen et al. (2014) and Emmons et al. (2016). However, the researchers added questions about camouflage-related traits. Children in both age groups generalised knowledge to a new species adaptation of a foraging trait. The

\footnotetext{
${ }^{1}$ The book is defined as a factual narrative picture storybook (Emmons et al. 2017). In this paper, this book is from now on referred to as "the storybook" or "the book".
} 
older children were able to transfer their knowledge of natural selection to both foraging and camouflage adaptation (Emmons et al. 2017).

In all studies concerning children's learning of evolution presented in this section, read aloud has served as an intervention, and children's learning have been evaluated after the read aloud. Consequently, none of the studies have focused on meaning-making processes occurring during the read aloud. This paper takes on a perspective on learning that interrogates the read aloud as an interactive context (cf. Wiseman 2011). This view is further explained in the next section.

\section{Theoretical Framework}

This paper adopts a perspective on meaning making about evolution that builds on previous work by Frejd (2018; 2019). Concepts are socially constructed meanings (cf. Tang 2011) that become visible through several modalities including talk and gestures, or through the use of materials (Jewitt et al. 2001), in collaborative interactions that emerge in situated practices (Ash 2004; Jewitt et al. 2001; Siry 2013). When children engage in science activities in small groups, they have the opportunity to share, build upon, and scaffold one another's ideas (Murphy et al. 2011). In this regard, meaning making takes place as multimodal practices "in between and around words, postures and gestures" (Taylor 2014, p. 408).

\section{Interactive Read Aloud and Meaning Making in Science}

Meaning making in interactive read aloud "extends beyond text delivery" (Oliveira et al. 2014, p. 665). Pictures in books do more than simply engage children during read aloud-pictures also serve as iconic resources that can be drawn upon in meaning-making processes. Comparatively, Frejd (2018) has shown that materials such as photographs, serve both as communicative tools and as resources providing meaning in discussions about evolution. The understanding of a story occurs within social interaction. In this regard, the reader and listeners cooperatively and interactively participate in negotiating the meaning of the story, a process referred to as interactive negotiation (Cochran-Smith 1984). In this paper, the process of interactive negotiation is seen as occurring within the context of interactive reading. In contrast to the view where books are seen as media that passively transfer knowledge to the reader and listener, interactive negotiation requires the meaning of the text to be "jointly worked out" (p. 260) through interaction by the reader and listeners in the form of asking questions and making comments about the text. One way of negotiating meaning of a story is to relate "life to text" by evoking personal experiences in relation to the story (Cochran-Smith 1984). Thus, interaction between children during read aloud can be seen as part of creating a context where children can make meaning together as a collective. That is, children are provided with the opportunity to draw from ideas informed by their own lives and understandings, and in this process, ideas are formed (Wiseman 2011).

As described, there is a large body of empirical work (e.g. Emmons et al. 2016; Emmons et al. 2017; Kelemen et al. 2014) that aims to use the book How the piloses evolved skinny noses (Kelemen and The Child Cognition Lab, 2017) as a scripted invention for learning evolution. This paper intend to shed light on the complex meaning-making processes occurring during interactive read aloud of science themes books. Therefore, the book How the piloses evolved skinny noses (Kelemen and The Child Cognition Lab 2017) is read in an 
interactive way to children in small groups. The study explores children's meaning making during interactive read aloud by investigating what the children focus on, and negotiate, during the interactive read aloud.

\section{Methods}

\section{Participants and Context}

Data was collected during a 2-week period in two preschool classes at a municipal school in Sweden with 24 children (9 girls, 15 boys). In Sweden, children enter preschool class (förskoleklass in Swedish) the year they turn 6 years of age. Preschool class is a preparatory year "in between" (Lago 2014) preschool and primary school, characterised by both by playbased and formal school practice. Science education in preschool class combines observations, systematic investigations, and posing questions. None of the participants received any previous formal instruction related to evolution prior to data collection. Consent to participate in the study was provided by caregivers and children.

\section{Data Collection}

The author designed and performed the data collection and analysed the data. The author is also an experienced teacher. To gain mutual trust with the participants, the author took part in both classes' work, had lunch, and participated in recess activities for a few days before the data collection commenced (Parkinson 2001).

Children participated in an interactive reading in groups of three $(N=8)$. The author (referred to from now on as "the reader") read the book to all the groups. The placement of the reader and children intended to give all children access to viewing the book's pictures (see Fig. 1). The reader applied dialogic reading strategies (Zevenbergen and Whitehurst 2003). For example, the reader asked questions such as "What do you think the piloses eat?" and rephrased the text. Children's questions and comments were embraced, and encouraged during the reading. This approach differed from Emmons et al. (2017), Emmons et al. (2016) and Kelemen et al. (2014), where no dialogic or interactive strategies were applied. The reading

Fig. 1 Screenshot from the video data showing the placement of the children and the reader in relation to the storybook during the read aloud

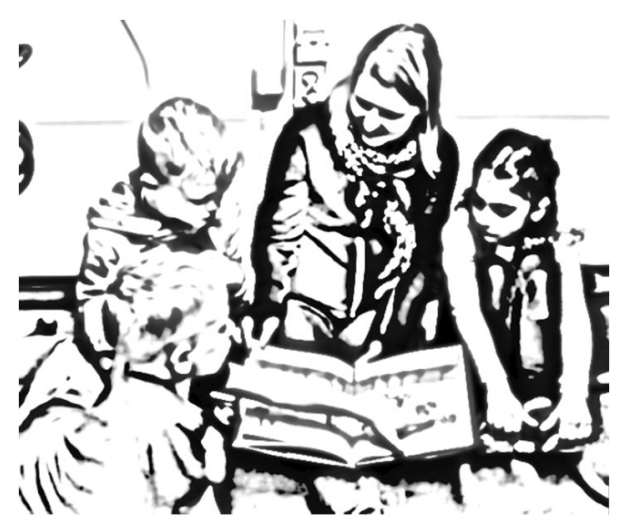


took approximately $10 \mathrm{~min}$. All reading sessions were video recorded in order to capture multimodal interaction including gestures made towards the book.

\section{The Book How the piloses evolved skinny noses}

How the piloses evolved skinny noses ${ }^{2}$ (Kelemen and The Child Cognition Lab 2017) can be compared to a picture book, since text and illustrations together makes out the story (Giorgis 1999). Each two-page spread of the book displays large images that occupy approximately $70 \%$ of the page space. Through images and text, the book communicates the following seven biological concepts related to natural selection:

- Trait variation inherent to a biological population - piloses have wide or skinny trunks.

- Ecological habitat and food-source change due to climate change - the weather changes and becomes very hot. Concurrently, the pilose food source (milli bugs) retreats down narrow tunnels.

- Differential health and survival due to differential access to food-piloses with skinny trunks are able to reach down the narrow tunnels. Piloses with wider trunks cannot reach down the narrow tunnels and becomes weak and often perish.

- Differential reproduction due to differential health - piloses with skinny trunks have two or more children while piloses with wider trunks have none or one child.

- The reliable transmission of heritable physical traits across generations - pilose children resemble their parents.

- The stability and constancy of inherited traits over the lifespan — piloses that are born with wide or skinny trunks have this feature throughout life.

- Trait-frequency changes (i.e. adaptation) over multiple generations - there is a gradual change in trait frequency across generations. At the end of the book there are more piloses with skinny trunks than with wider trunks. (Emmons et al. 2017, p. 7).

In preparation for the current study, the book text was translated into Swedish in collaboration with three researchers. The translation aimed to capture the exact scientific meaning of the original version in line with a Swedish 6-year old's vocabulary.

\section{Analytical Process}

Research concerned with children's learning of evolutionary concepts often is coupled with cognitive, not interactive, perspectives on learning. Within this body of research (e.g. Emmons et al. 2016; Kelemen et al. 2014; Legare et al. 2013; Shtulman et al. 2016), children's reasoning often are labelled as correct or as holding "misconceptions" associated with teleological or creationist views on the origin of species. In taking on an interactive perspective on meaning making, this paper explores what the children focus on during the interactive read aloud, without determining if their focus is scientifically "right" or "wrong". Therefore, terms associated with "misconceptions" were purposefully not used in the analysis. Based on the theoretical perspective applied in this paper, children's meaning making about evolution during the interactive reading was explored through analysing the children's and the reader's multimodal interaction (Ash 2004).

\footnotetext{
$\overline{{ }^{2} \text { https://www.youtube.com/watch? }}=$ nUyVd1pO3nI
} 


\section{Transcriptions}

All interactive readings were transcribed using a multimodal approach (Jewitt et al. 2001) including gestures made towards the book. In the transcripts, text printed in the book (and read aloud by the reader in Swedish) is provided in italics. The text displays the storybook's original text in English. Interaction taking place outside the text is written with normal font. Non-verbal actions are described within parenthesis. Clarifying notes are given within square brackets (Table 1).

\section{Coding Procedure}

In capturing what the children focus on during the read aloud, the coding was conducted in terms of child initiated turns (Oyler 1996). A turn is defined as beginning when a child starts to talk, or performs some other communicative action, and ends when another person starts to perform some communicative action (Hogan et al. 1999). To be defined as child initiated, the turn should introduce a different topic than the preceding turn (Oyler 1996). In line with Oyler, utterances that reintroduced a previous topic were coded as child initiated if there had been at least one turn changing the topic in between. If a child reacted on a question posed in the text or by the reader, this was not coded as a child initiated turn.

\section{Topics Introduced by Children}

Each turn was labelled with a descriptive code. Scientific concepts, such as "variation", were used when applicable. Thus, "variation" was not a word used by the children. In total, 14 codes were generated during the analysis (see Table 2). Codes that did not fit the coding scheme were coded as "Other". Such turns included utterances such as "wow" and one sequence where two children talked about lava - content unrelated to the book. In total, 12 turns were coded as "Other".

All topics were contrasted with the seven biological concepts described in the storybook (see the section "The book How the piloses evolved skinny noses"). This analysis revealed that seven topics were linked to the biological concepts presented in the book (Table 2). However, six of the child-initiated topics were not directly related to the biological concepts described in the book. The number of turns targeting each topic was noted, providing information about the children's focus during the interactive reading as a whole. Table 2 describes the child-initiated topics and links to the biological concepts described in the storybook. Examples of each topic are provided in the results section.

Table 1 Example of the transcript convention used in the transcripts

\begin{tabular}{|c|c|}
\hline Reader: & They were all piloses, but they looked a little bit different from each other. \\
\hline Adam: & $\begin{array}{l}\text { Yes, because these had more thick [trunks] like this } \\
\text { (points at several wide trunked piloses on the first page) }\end{array}$ \\
\hline R: & $\begin{array}{l}\text { Exactly. Many of (points at two wide trunked piloses) } \\
\text { the piloses had wider trunks, and only a small number had thinner trunks } \\
\text { (points at a pilose with a thin trunk on the second page) }\end{array}$ \\
\hline Bim: & And long \\
\hline
\end{tabular}

Name or initial of the relative participant is shown in the left column. Text is stated in italics. Interaction outside the text is stated in lower case. Parentheses show non-verbal communication and brackets show clarifying notes 


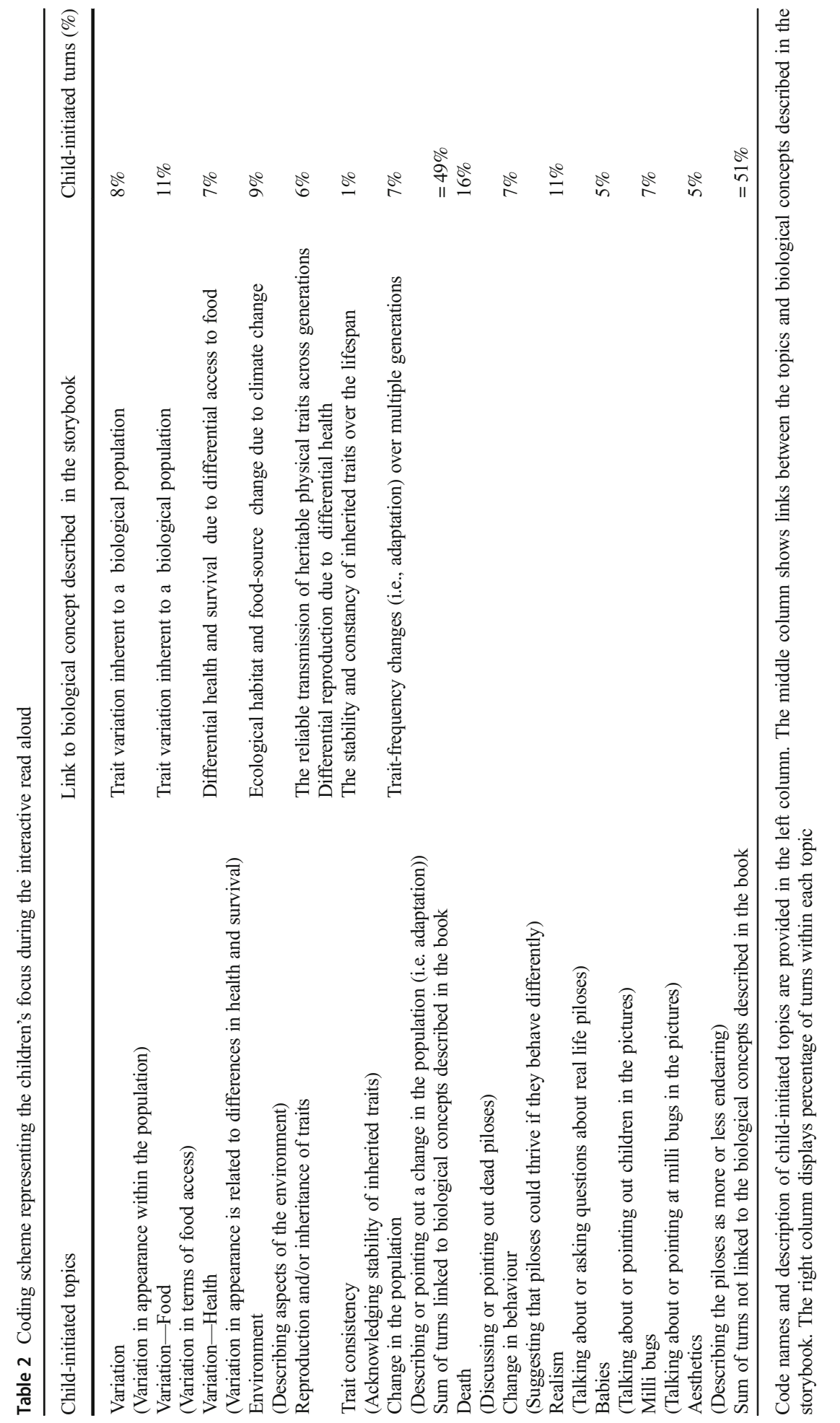




\section{Results}

\section{Topics Linked to Natural Selection in the Book}

Seven topics focused by the children were linked to the biological concepts presented in the book (Table 2). The children talked about variation among the piloses in several ways. For example, they pointed at the book's pictures as they described similarities and differences in appearances (variation) and made connections between trunk type in relation to access to food (variation-food). The children repeatedly pointed out examples of piloses in the pictures that "could" or "could not" reach their trunks down the tunnels. In addition, the children suggested that piloses with wider trunks were tired or may even perish (variation-health). In total, $26 \%$ of all turns exhibited variation in some manner. When the children talked about variation (variation, variation - food, and variation - health), they used the book's pictures as communicative tools and as resources for providing meaning (Frejd 2018).

The storybook describes that the piloses' habitat and food-source changed due to climate change. Linked to this biological concept was the topic environment (9\% of all turns), which was in focus when children pointed out details in the pictures and followed the story. However, the children also questioned the fact that the environment changed so drastically. For example, one child claimed that she "thinks that there is grass over there" as she pointed at the horizon on the picture. As in the turns concerning variation, the book served as a communicative resource and as a resource for providing meaning. Therefore, the pictures served as iconic resources in the children's meaning making (cf. Oliveira et al. 2014).

During the interactive read aloud, the children paid attention to the fact that piloses reproduce and have children (reproduction and/or inheritance of traits, $6 \%$ of all turns). This was mostly acknowledged by the children that pointed out resemblances between pilose adults and children in the pictures. Despite being repeatedly mentioned in the storybook, trait consistency emerged as the least child-initiated topic. Only one child initiated trait consistency as a topic (1\% of all turns). This initiation was a reaction to the reader rephrasing the text about piloses having the same trait throughout life. The child interrupted the reader and asked what would happen if the pilose's trunk was cut off. This initiation put forward a rather different perspective on trait consistency compared with how it is described in the book. While the book describes trait consistency as stability and constancy of inherited traits over the lifespan, the child initiated trait consistency in relation to external circumstances.

Seven percent of the turns concerned change in population. Excerpt 1 reveals how Timmy (T) and the reader $(\mathrm{R})$ interactively negotiated this topic and how the book's pictures were engaged during this process.

As shown in Excerpt 1, the book describes that wide-trunk piloses have less children than skinny-trunk piloses. During the reading, Timmy looks at the pictures and reacts to them. $\mathrm{He}$ points to and engages the pictures as he says that there are a few wide-trunk piloses (line 6-7 and 12-14, image 1). The turns in these exchanges concern the topic variation. The reader confirms Timmy's observation (line 8 and 15). Timmy then concludes that "now" there are many skinny trunked piloses (line 16-17). Subsequently, this initiates the topic change in population. Again, the reader confirms Timmy's assertion, this time by repeating what he said. Timmy extends his idea by adding that there are "super super many" babies. At this stage, Timmy moves his hand across the page spread (image 2), using the picture as a communicative tool (Frejd 2018). The reader continues to confirm Timmy's observation and adds that there are fewer piloses with wider trunks. Timmy quickly counts the wider trunked piloses to suggest 

$\mathrm{R}:$
And then this cycle happened again and again. Piloses with thinner trunks got more food so they were healthy enough to have lots of children who were born with thinner trunks like they were. These children then grew up
T: $\quad$ Oh! (points to a wide trunked pilose with one child) There's only one that has [a wide trunk] like that.
$\mathrm{R}:$ Yes, to be adults with thinner trunks and had lots more children. Piloses with wider trunks had trouble getting food so they were less healthy and had less children.
T: $\quad$ It was that one (points to a wide trunked pilos and its child - image 1) and that one (points to another wide trunked pilose and its child) that had [wide trunks].
R: Yes.
T: (moves his hand across the skinny trunked piloses in the picture) So now there are really many like these.
$\mathrm{R}$ : Now, there are many with skinny trunks, yeah.
$\mathrm{T}$ : $\quad$ (moves his hand across the whole picture - image 2) If one were to count all the babies, there would be super super many.
R: $\quad$ Yes, there are many with skinny trunks, but not so many with wider trunks.
T: No, only four

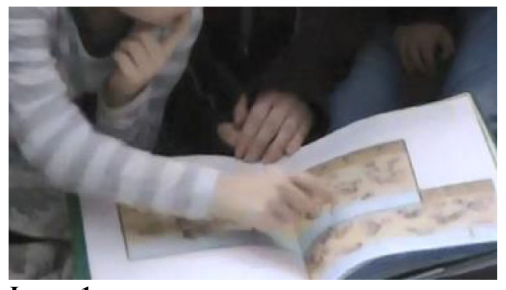

Image 1

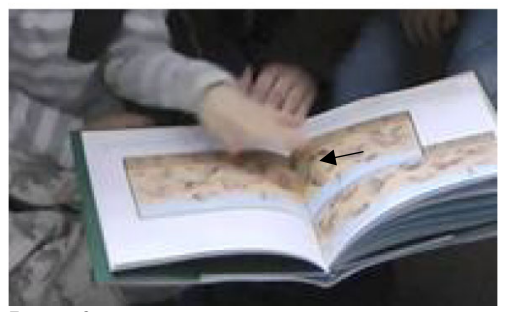

Image 2

Excerpt 1 Timmy and the reader. Accompanying video screenshots are provided in the right-hand column. Links to images are in bold text. Arrow depicts direction of gesture

the presence of four individuals (line 24). The book's pictures are an essential meaning making component of this negotiation of the topic change in population. The storybook's pictures display trait-frequency changes over multiple generations. Consequently, Timmy had the possibility to point at the pictures and count the piloses with thinner and wider trunks respectively and discern that they had increased or decreased.

All the biological concepts described in the book were identified in the child initiated topics at some point in the study. Apart from the biological concepts, other topics emerged during the read aloud. These topics are further described in the next section.

\section{Additional meaning-making topics evoked by the interactive reading}

In approximately $51 \%$ of all child initiated turns, the children focused on aspects other than the seven biological concepts contained in the book, namely death, change in behaviour, realism, babies, milli bugs, and aesthetics (Table 2). Although these topics are not directly related to the original biological concepts, their salient emergence during the interactive read aloud displays additional perspectives on children's meaning-making processes.

The topic with the greatest focus was death (16\%). Pointing out dead or dying piloses was a common behaviour among the children. In this regard, one spread in the storybook includes the display of two piloses that are lying down (Fig. 2).

Several children negotiated the meaning of the images in Fig. 2. In this regard, Excerpt 2 represents such negotiation between Frank $(\mathrm{F})$, Tilly $(\mathrm{T})$, and Jonah $(\mathrm{J})$ :

In Excerpt 2, the storybook describes the biological concepts differential reproduction due to differential health (line 4-5, 8-9, and 12-13) and the reliable transmission of heritable physical traits across generations (line 19 and 22). However, the children react to the accompanying pictures of this part of the book with the focus on death. In several lines (1, 7, 16-18, 20-21, 24-25), all three children point at the dead piloses. In line 16-17, Frank quickly points to one adult pilose with a wide trunk and to the pilose lying down on the right 

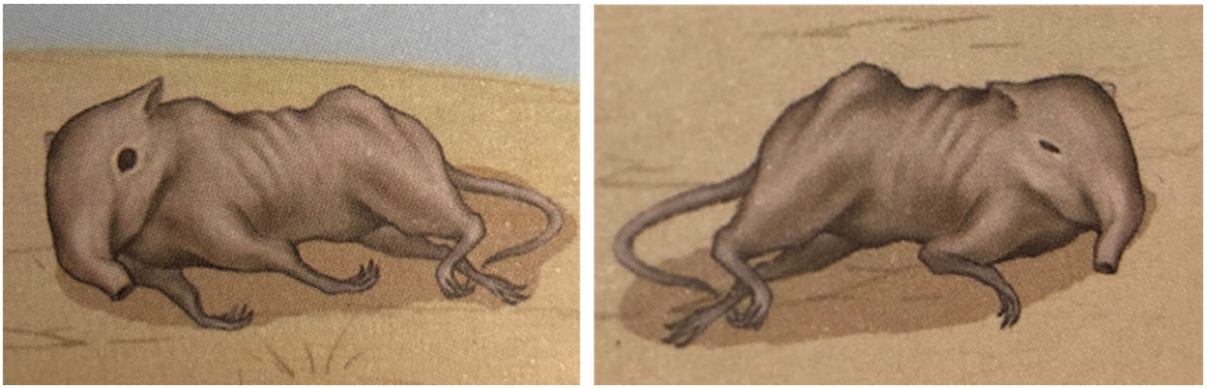

Fig. 2 Images of two piloses lying down (Kelemen and The Child Cognition Lab 2017, pp. 14-15). The pilose on the left has its eyes open while the pilose on the right has its eyes closed

(image 3 and 4). This could be interpreted as if he connects wide trunks to death. Despite the different foci in the storybook's text and limited response from the reader, the children continue to initiate the death topic. This persistence implies that it is meaningful for the children to negotiate which piloses are and are not dead by pointing to the pictures in the book. The reader briefly acknowledge the children (e.g. by humming, line 19), but does not stop to discuss the topic until line 26. The reader states that the pilose is "very ill, at least". Jonah suggest that the pilose with closed eyes "is dead anyway" (line 30, image 5). Thus, the display of the eyes of the piloses seems to signal a difference between the two piloses lying down (i.e.

\begin{tabular}{|c|c|}
\hline $\mathrm{F}$ : & $\begin{array}{l}\text { (points at a pilose that is lying down) Here was } \\
\text { [inaudible] }\end{array}$ \\
\hline $\mathrm{R}:$ & $\begin{array}{l}\text { Yes. (Points at the same pilose as child 1) It doesn't } \\
\text { feel very well, huh. Some piloses with wider } \\
\text { trunks were very weak. }\end{array}$ \\
\hline & $\begin{array}{l}\text { (leans forward and looks at the pilose that Frank } \\
\text { and the reader have talked about) It is dead. }\end{array}$ \\
\hline $\mathrm{R}:$ & $\begin{array}{l}\text { They were so unhealthy that they died before } \\
\text { having any children. But other piloses }\end{array}$ \\
\hline $\mathrm{T}:$ & $\begin{array}{l}\text { (Points at a skinny trunk pilose with two children } \\
\text { and grins) }\end{array}$ \\
\hline $\mathrm{R}:$ & $\begin{array}{l}\text { with wider trunks were only healthy enough to } \\
\text { have one child. Do you see? (points at a wide } \\
\text { trunk pilose with one child) The wide [trunk } \\
\text { piloses] only have one child. }\end{array}$ \\
\hline $\mathrm{F}:$ & $\begin{array}{l}\text { Here (points at the wide trunk pilose with one child } \\
\text { and the right pilose that is lying down - image } 3 \text { and } \\
\text { 4, fig. 2) }\end{array}$ \\
\hline $\begin{array}{l}\text { R: } \\
\text { F: }\end{array}$ & $\begin{array}{l}\text { Mmm. And that child was born with a wider trunk } \\
\text { (points at the pilose that is lying down again) Is it } \\
\text { dead? }\end{array}$ \\
\hline $\mathrm{R}:$ & $\begin{array}{l}\text { (nods) Because its parents were born with a wider } \\
\text { trunk. }\end{array}$ \\
\hline $\mathrm{T}:$ & $\begin{array}{l}\text { (Points at the left pilose that is lying down) He is } \\
\text { dead too. }\end{array}$ \\
\hline R: & $\begin{array}{l}\text { You think? Or very ill, at least. It looks very } \\
\text { skinny (points at the left pilose). You can see the } \\
\text { ribs on it. }\end{array}$ \\
\hline $\mathrm{J}:$ & $\begin{array}{l}\text { That one (points at the right pilose that is lying } \\
\text { down - image 5, fig. 2) is dead anyway. }\end{array}$ \\
\hline
\end{tabular}
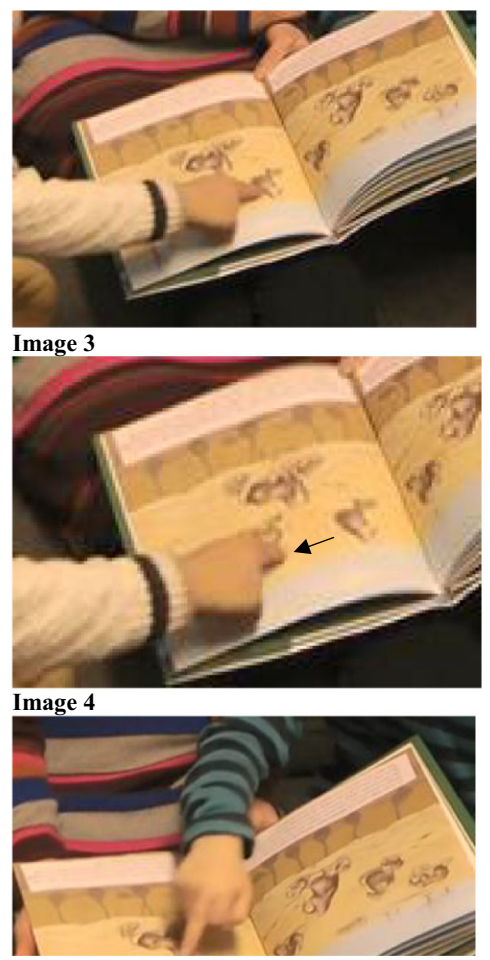

Excerpt 2 Frank, Tilly, Jonah, and the reader. Screenshots from the video are provided in the right-hand column. Links to images are shown in bold. Arrow shows direction of gesture. Bracket to the left show simultaneous turns 
one is dead and one is not). The children's attention to details in the pictures are also central in the topics milli bugs and babies. The children point at the milli bugs and the pilose children (which were called "babies" by the participating children) and count them. They also talked about the milli bugs' behaviour and habitat.

The topics change in behaviour (7\%) and realism (11\%) also emerged frequently. In both topics, the children connected the storybook to the real world. Here, the children asked about the size of piloses, their food source, and how to tell the difference between mothers and fathers. Furthermore, the children suggested that the piloses could alter their behaviour, for example dig for milli bugs instead of just using their trunks, or walk to another location where they might find other food. This can be seen as an example of how the children describe change in behaviour as a way to adapt to new environments. Some children also indicated altruistic aspects in their responses by suggesting that the piloses should help each other and asked questions about whether adults did not help their children.

\section{Discussion}

Previous work (Emmons et al. 2017; Emmons et al. 2016; Kelemen et al. 2014) has shown that children as young as 5 years of age are able to form a basic understanding of evolution after listening to the storybook How the piloses evolved skinny noses (Kelemen and The Child Cognition Lab 2017). However, these studies have been conducted in highly scripted settings, where children have been read to and interviewed one-on-one. In contrast, this paper has applied a more authentic classroom approach-interactive read aloud in small groups. In building on previous findings by Frejd showing the role of interaction (2019) and semiotic resources (2018) in meaning making about evolution, this paper extends existing research by offering a semiotic exploration preschool children's meaning making during an interactive read aloud.

This study does not intend to measure children's learning gains, as might be the case in investigations focused on defining the cognitive variables among children that learn about evolution (e.g. Emmons et al. 2017). While the cognitive approach certainly have merits for informing practice (e.g. Kelemen et al. 2014), this paper emphasises processes occurring in interaction (Siry 2013) rather than learning outcomes per se. Therefore, focus is not to discern to what extent children "understand" natural selection after participating in the interactive reading. Nevertheless, the analysis shows that all seven biological concepts described in the book are exposed and negotiated at some point (see Table 2). The children in this study expose the concepts in interaction during the read aloud, which confirms that children as young as 6 years old are capable of talking about biological topics related to natural selection and evolution (Emmons et al. 2017; Emmons et al. 2016; Kelemen et al. 2014).

Previous studies suggest that children have difficulties with acknowledging within-species variation (e.g. Emmons et al. 2017). The findings reported in this paper demonstrates that during interactive read aloud, child-initiated discussions about variation were frequent and targeted within-species variation, variation in access of food, and variation in health and death. One explanation for the high prevalence of talk related to variation might be that the children had direct view of the book's pictures. The pictures in the book go far beyond an aid to maintain focus - they serve as communicative tools and as resources to provide meaning when topics are initiated and negotiated. This confirms the findings from (Oliveira et al. 2014), which show that access to pictures makes meaning making extend beyond the written text as 
life experiences are included. In other words, the book serves as a rich semiotic resource (Van Leeuwen 2005). Nevertheless, if we want children to be able to use the book's pictures as semiotic resources to discuss variation, they need to be able to reach and physically engage with the book, and the reader needs to encourage them to make comments and ask questions (Gardner-Neblett et al. 2017). Here, group size becomes important - small groups provides "elbowroom" to interact with the book, peers, and the reader. Concurrently, the reader has the possibility to consider children's reactions to the book (Morrow and Smith 1990).

In extending earlier research (Emmons et al. 2017; Emmons et al. 2016; Kelemen et al. 2014), this paper reveals that children focus on other topics in their meaning making apart from the biological concepts, namely death, change in behaviour, realism, babies, milli bugs, and aesthetics. This finding suggests that when read in an interactive way, the storybook about natural selection becomes something more than an instructional description of natural selection. The storybook also serves as a tool to evoke responses concerning altruism, death, and how animals can act to survive. Thus, the interactive reading approach does not remove the biological content described in the book but induced the emergence of additional topics. Therefore, this study shed light on the complexity of children's meaning-making processes. Children's meaning-making processes are often not restricted to the teacher's intention or focus, but they also contain multiple children's views of life (see the notion of working theories in Peters and Davis 2011). In this study, the children focus on detail and relate the story to the real world, connecting "life to text" (Cochran-Smith 1984). The children also questioned the book when there was a dissonance between the child's view of the world and the book's description of the world. For example, the children suggested that the piloses should alter their behaviour to access food, which was not mentioned as an option in the storybook. Thus, the emergent child-centric focus creates "third spaces" (Varelas et al. 2014) that affect how children make meaning about evolution and that supports meaning making by allowing children to take part in constructing the story.

In conclusion, this paper shows that children engage in meaning making about natural selection when participating in interactive read aloud. However, the sample groups are small. As mentioned, group size affects children's actions during interactive read aloud. Therefore, the findings reported in this study are not necessarily transferable to larger groups of children (cf. Morrow and Smith 1990) and to all interactive read aloud contexts. In addition, it is likely that children with other experiences might initiate other topics than those described in this study.

Based on the findings of this paper, two implications for teaching practice are suggested. Firstly, by acknowledging what children focus on during read aloud, teachers have the possibility to build on the intended focus (Oyler 1996). Furthermore, acknowledging children's own role in the read aloud can motivate children to engage in meaning making. Conversely, if we merely view storybooks as tools for transferring science knowledge, we might lose the opportunity to embrace questions that are important for children. Secondly, allowing children access to pictures showing variation in populations while giving children the authority to talk about these pictures may stimulate discussions and meaning making about within-species variation. Future work will explore how the same cohort of children uses what they learned about evolution during the interactive read aloud in a subsequent modeling activity. This future study shall build upon a meaning making perspective to explore children's representational and relational aspects in their transfer of evolutionary concepts. 
Acknowledgements The author is grateful to Professor Deborah Kelemen for her support and description of the development of the How the piloses evolved skinny noses storybook. Images from the storybook that appear in Fig. 2, Excerpt 1, and Excerpt 2 are reproduced with permission from Tumblehome Learning, Inc. and are based on the work of Professor Deborah Kelemen (supported by NSF Grants REC-0529599, DRL-1007984, DRL1561401). The author thanks the children who participated in the current study, without whom this work would not have been possible.

Funding Information Open access funding provided by Linköping University.

\section{Compliance with Ethical Standards}

Conflict of Interest The author declares that she has no conflict of interest.

Open Access This article is distributed under the terms of the Creative Commons Attribution 4.0 International License (http://creativecommons.org/licenses/by/4.0/), which permits unrestricted use, distribution, and reproduction in any medium, provided you give appropriate credit to the original author(s) and the source, provide a link to the Creative Commons license, and indicate if changes were made.

\section{References}

Ash, D. (2004). Reflective scientific sense-making dialogue in two languages: the science in the dialogue and the dialogue in the science. Science Education, 88(6), 855-884. https://doi.org/10.1002/sce.20002.

Browning, E., \& Hohenstein, J. (2015). The use of narrative to promote primary school children's understanding of evolution. Education 3-13. International Journal of Primary, Elementary and Early Years Education, 43(5), 530-547. https://doi.org/10.1080/03004279.2013.837943.

Cekaite, A., \& Björk-Willén, P. (2018). Enchantment in storytelling: co-operation and participation in children's aesthetic experience. Linguistics and Education, 48, 52-60. https://doi.org/10.1016/j.linged.2018.08.005.

Cochran-Smith, M. (1984). The making of a reader. New Jersey: Ablex Publishing Corporation.

Emmons, N., Smith, H., \& Kelemen, D. (2016). Changing minds with the story of adaptation: Strategies for teaching young children about natural selection. Early Education and Development, 27(8), 1205-1221. https://doi.org/10.1080/10409289.2016.1169823.

Emmons, N., Lees, K., \& Kelemen, D. (2017). Young children's near and far transfer of the basic theory of natural selection: an analogical storybook intervention. Journal of Research in Science Teaching, 55(3), 321-347. https://doi.org/10.1002/tea.21421.

Frejd, J. (2018) “If It Lived Here, It Would Die.” Children's Use of Materials as Semiotic Resources in Group Discussions About Evolution. Journal of Research in Childhood Education , 32(3), 251-267

Frejd, J. (2019). When Children Do Science: Collaborative Interactions in Preschoolers' Discussions About Animal Diversity. Research in Science Education, https://doi.org/10.1007/s11165-019-9822-3.

Gardner-Neblett, N., Holochwost, S. J., Gallagher, K. C., Iruka, I. U., Odom, S. L., \& Bruno, E. P. (2017). Books and toddlers in child care: under what conditions are children most engaged? Paper presented at the child \& youth care forum.

Giorgis, C. (1999). The power of reading picture books aloud to secondary students. The Clearing House, 73(1), 51-53. https://doi.org/10.1080/00098659909599640.

Hogan, K., Nastasi, B. K., \& Pressley, M. (1999). Discourse patterns and collaborative scientific reasoning in peer and teacher-guided discussions. Cognition and Instruction, 17(4), 379-432. https://doi.org/10.1207 /S1532690XCI1704_2.

Jewitt, C., Kress, G., Ogborn, J., \& Tsatsarelis, C. (2001). Exploring learning through visual, actional and linguistic communication: the multimodal environment of a science classroom. Educational Review, 53(1), $5-18$.

Johanna Frejd, (2018) "If It Lived Here, It Would Die." Children's Use of Materials as Semiotic Resources in Group Discussions About Evolution. Journal of Research in Childhood Education 32 (3):251-267

Kalogiannakis, M., Nirgianaki, G.-M., \& Papadakis, S. (2018). Teaching magnetism to preschool children: The effectiveness of picture story reading. Early Childhood Education Journal, 46(5), 535-546. https://oi. org/10.1007/s10643-017-0884-4. 
Kelemen, D., \& The Child Cognition Lab. (2017). How the piloses evolved their skinny noses. Boston, MA: Tumblehome Learning.

Kelemen, D., Emmons, N. A., Seston Schillaci, R., \& Ganea, P. A. (2014). Young children can be taught basic natural selection using a picture-storybook intervention. Psychological Science, 25(4), 893-902. https://doi. org/10.1177/0956797613516009.

Lago, L. (2014). "Mellanklass kan man kalla det”: Om tid och meningsskapande vid övergången från förskoleklass till årskurs ett. (Doctoral thesis). Linköping: Linköping University.

Legare, C. H., Lane, J. D., \& Evans, E. M. (2013). Anthropomorphizing science: how does it affect the development of evolutionary concepts? Merrill-Palmer Quarterly, 59(2), 168-197. https://doi. org/10.13110/merrpalmquar1982.59.2.0168.

Lennox, S. (2013). Interactive read-alouds - an avenue for enhancing children's language for thinking and understanding: a review of recent research. Early Childhood Education Journal, 41(5), 381-389. https://oi. org/10.1007/s10643-013-0578-5.

Leung, C. B. (2008). Preschoolers' acquisition of scientific vocabulary through repeated read-aloud events, retellings, and hands-on science activities. Reading Psychology, 29(2), 165-193. https://doi.org/10.1080 $/ 02702710801964090$.

Morrow, L. M., \& Smith, J. K. (1990). The effects of group size on interactive storybook reading. Reading Research Quarterly, 25(3), 213-231.

Murphy, C., Murphy, C., \& Kilfeather, P. (2011). Children making sense of science. Research in Science Education, 41(2), 283-298. https://doi.org/10.1007/s11165-010-9165-6.

Oliveira, A. W., Rivera, S., Glass, R., Mastroianni, M., Wizner, F., \& Amodeo, V. (2014). Multimodal semiosis in science read-alouds: extending beyond text delivery. Research in Science Education, 44(5), 651-673. https://doi.org/10.1007/s11165-013-9396-4.

Oyler, C. (1996). Sharing authority: student initiations during teacher-led read-alouds of information books. Teaching and Teacher Education, 12(2), 149-160. https://doi.org/10.1016/0742-051X(95)00028-I.

Parkinson, D. D. (2001). Securing trustworthy data from an interview situation with young children: six integrated interview strategies. Child Study Journal, 31(3), 137-156.

Peters, S., \& Davis, K. (2011). Fostering children's working theories: pedagogic issues and dilemmas in New Zealand. Early Years, 31(1), 5-17. https://doi.org/10.1080/09575146.2010.549107.

Shtulman, A., Neal, C., \& Lindquist, G. (2016). Children's ability to learn evolutionary explanations for biological adaptation. Early Education and Development, 27(8), 1222-1236. https://doi.org/10.1080 /10409289.2016.1154418.

Siry, C. (2013). Exploring the complexities of children's inquiries in science: knowledge production through participatory practices. Research in Science Education, 43(6), 2407-2430. https://doi.org/10.1007/s11165013-9364-z.

Smolkin, L. B., \& Donovan, C. A. (2003). Supporting comprehension acquisition for emerging and struggling readers: the interactive information book read-aloud. Exceptionality, 11(1), 25-38. https://doi.org/10.1207 /S15327035EX1101_3.

Tang, K.-S. (2011). Reassembling curricular concepts: a multimodal approach to the study of curriculum and instruction. International Journal of Science and Mathematics Education, 9(1), 109-135. https://doi. org/10.1007/s10763-010-9222-7.

Taylor, R. (2014). Meaning between, in and around words, gestures and postures - multimodal meaning-making in children's classroom discourse. Language and Education, 28(5), 401-420. https://doi.org/10.1080 /09500782.2014.885038.

Van Leeuwen, T. (2005). Introducing social semiotics. London: Routledge.

Varelas, M., Pieper, L., Arsenault, A., Pappas, C. C., \& Keblawe-Shamah, N. (2014). How science texts and hands-on explorations facilitate meaning making: learning from Latina/o third graders. Journal of Research in Science Teaching, 51(10), 1246-1274. https://doi.org/10.1002/tea.21173.

Wiseman, A. (2011). Interactive read alouds: teachers and students constructing knowledge and literacy together. Early Childhood Education Journal, 38(6), 431-438. https://doi.org/10.1007/s10643-010-0426-9.

Zevenbergen, A. A., \& Whitehurst, G. J. (2003). Dialogic reading: a shared picture book reading intervention for preschoolers. In A. van Kleeck, S. A. Stahl, \& E. B. Bauer (Eds.), On reading books to children: Parents and teachers (pp. 177-200). London: Lawrence Earlbaum Associates Inc, Publishers.

Publisher's Note Springer Nature remains neutral with regard to jurisdictional claims in published maps and institutional affiliations. 